\title{
Stabilization of unstable reentrant atrial tachycardias via fractionated continuous electrical activity ablation (CHAOS study).
}

\author{
Eduardo Franco ${ }^{1}$, Cristina Lozano ${ }^{2}$, Roberto Matía ${ }^{3}$, Antonio Hernandez-Madrid ${ }^{4}$, \\ Inmaculada Sánchez ${ }^{3}$, Jose Zamorano ${ }^{5}$, and Javier Moreno ${ }^{6}$ \\ ${ }^{1}$ Hospital Ramón y Cajal \\ ${ }^{2}$ University Hospital Ramón y Cajal \\ ${ }^{3}$ Ramón y Cajal Hospital \\ ${ }^{4}$ Ramon y Cajal hospital \\ ${ }^{5}$ Ramon y Cajal Hospital \\ ${ }^{6}$ San Carlos University Hospital
}

January 31, 2021

\begin{abstract}
Introduction. Unstable reentrant atrial tachycardias (ATs) (i.e. those with frequent circuit modification or conversion to atrial fibrillation) are challenging to ablate. We have tested a strategy to achieve arrhythmia stabilization into mappable stable ATs based on the detection and ablation of rotors. Methods and Results. From May 2017 to December 2019, 97 consecutive patients with reentrant ATs were ablated. Of these, 18 (18.6\%) presented unstable circuits and were included. Mapping was performed using conventional high-density mapping catheters (IntellaMap ORION, PentaRay NAV or Advisor HD Grid). Rotors were subjectively identified as fractionated continuous (or quasi-continuous) electrograms on 1-2 adjacent bipoles of the mapping catheter, without dedicated software. 13 patients $(72 \%)$ had detectable rotors (median 2 [1-3] rotors per patient); focal ablation achieved conversion into stable AT or sinus rhythm in $12(92 \%)$. In the other 6 patients, sites with spatiotemporal dispersion (i.e. all the cycle length comprised within the mapping catheter) plus non-continuous fractionation on single bipoles were targeted. 17 sites with spatiotemporal dispersion were detected and focally ablated. Globally, and excluding 1 patient with spontaneous AT stabilization, ablation success to stabilize the AT was achieved in 16/17 patients (94.1\%). One-year freedom from atrial arrhythmias was similar between patients with unstable and stable ATs $(66.7 \%$ Vs $65.8 \%$, p=0.946). Conclusion. Most unstable reentrant ATs show detectable rotors, identified as sites with single-bipole fractionated quasi-continuous signals, or spatiotemporal dispersion plus non-continuous fractionation. Ablation of these sites is highly effective to stabilize the AT or convert it into sinus rhythm.
\end{abstract}

Stabilization of unstable reentrant atrial tachycardias via fractionated continuous electrical activity ablation (CHAOS study).

Authors: Eduardo Franco, MD, PhD, ${ }^{*}$ Cristina Lozano Granero, $\mathrm{MD},{ }^{*}$ Roberto Matía, MD, PhD, ${ }^{*}$ Antonio Hernández-Madrid, MD, PhD, ${ }^{*}$ Inmaculada Sánchez, MD, ${ }^{+}$Jose Luis Zamorano, MD, PhD, ${ }^{*}$ Javier Moreno, $\mathrm{MD}, \mathrm{PhD}^{*}$.

* Arrhythmia Unit. Cardiology Department. University Hospital Ramon y Cajal. Madrid, Spain.

+ Pediatric Cardiology Department. University Hospital Ramon y Cajal. Madrid, Spain.

Corresponding author: Eduardo Franco, MD, PhD. 
Arrhythmia Unit. Cardiology Department. University Hospital Ramon y Cajal.

Postal address: Carretera de Colmenar Viejo, Km 9.100. ZIP: 28034. Madrid, Spain.

Tel: +34913369006. Fax: +34913368515. E-mail: efranco@academiamir.com

Financial support : none

Disclosures : Dr. Eduardo Franco has received consulting fees from Biosense Webster. Dr. Javier Moreno has received consulting fees from Boston Medical, Abbott Medical and Biosense Webster. The rest of the authors declare no conflicts of interest.

\section{ABSTRACT}

Introduction. Unstable reentrant atrial tachycardias (ATs) (i.e. those with frequent circuit modification or conversion to atrial fibrillation) are challenging to ablate. We have tested a strategy to achieve arrhythmia stabilization into mappable stable ATs based on the detection and ablation of rotors.

Methods and Results. From May 2017 to December 2019, 97 consecutive patients with reentrant ATs were ablated. Of these, 18 (18.6\%) presented unstable circuits and were included. Mapping was performed using conventional high-density mapping catheters (IntellaMap ORION, PentaRay NAV or Advisor HD Grid). Rotors were subjectively identified as fractionated continuous (or quasi-continuous) electrograms on 1-2 adjacent bipoles of the mapping catheter, without dedicated software. 13 patients $(72 \%)$ had detectable rotors (median $2[1-3]$ rotors per patient); focal ablation achieved conversion into stable AT or sinus rhythm in $12(92 \%)$. In the other 6 patients, sites with spatiotemporal dispersion (i.e. all the cycle length comprised within the mapping catheter) plus non-continuous fractionation on single bipoles were targeted. 17 sites with spatiotemporal dispersion were detected and focally ablated. Globally, and excluding 1 patient with spontaneous AT stabilization, ablation success to stabilize the AT was achieved in 16/17 patients (94.1\%). One-year freedom from atrial arrhythmias was similar between patients with unstable and stable ATs $(66.7 \%$ Vs $65.8 \%, \mathrm{p}=0.946)$.

Conclusion. Most unstable reentrant ATs show detectable rotors, identified as sites with single-bipole fractionated quasi-continuous signals, or spatiotemporal dispersion plus non-continuous fractionation. Ablation of these sites is highly effective to stabilize the AT or convert it into sinus rhythm.

\section{KEYWORDS}

Clinical: Catheter ablation - atrial tachycardia; Clinical: Catheter ablation - atrial flutter; Rotor; Highdensity mapping.

\section{INTRODUCTION}

Reentrant atrial tachycardias (ATs), excluding cavotricuspid isthmus (CTI)-dependent atrial flutter, can be challenging to map, especially in unstable circuits (i.e. those with frequent circuit modification or conversion to atrial fibrillation (AF)). These cases, which count for up to $15-20 \%,{ }^{1,2}$ are considered non-mappable and ablation is frequently not attempted. Electrical cardioversion and re-induction of the clinical AT can be tried, but arrhythmia induction and stabilization is often difficult to achieve. Class Ic antiarrhythmic agents can be used for this purpose ${ }^{3}$ but modification of atrial conduction properties can lead to non-clinical ATs. Other strategy is to perform substrate mapping and ablation in sinus rhythm. ${ }^{4}$

Patients with unstable circuits have been excluded from most reentrant AT ablation series, which have focused on mappable circuits. ${ }^{1,2,5-9}$ These patients are frequently considered untreatable with ablation, and this may lead to stopping rhythm control and accepting the atrial arrhythmia is permanent. During the last years, ablation strategies that try to terminate AF, the 'most unstable' atrial arrhythmia, via identification and ablation of AF drivers (rotational or focal), have emerged. ${ }^{10}$ Another approach is ablate areas with electrical spatiotemporal dispersion (STD), as a surrogate of local rotational activation. ${ }^{11}$ Given the known relationship between atrial fibrillation and reentrant $\mathrm{ATs},{ }^{12}$ we hypothesized that these strategies, specifically ablation 
of sites with rotational activation (i.e. rotors), might as well be used to stabilize or terminate unstable reentrant ATs.

The Conversion of Hardly mappable Atrial tachycardias via rOtor ablation into Sinus rhythm (CHAOS) study was a prospective single-center study, designed to test an ablation strategy in patients with unstable reentrant ATs based on the ablation of rotors, which were subjectively identified with conventional highdensity mapping catheters as sites with fractionated quasi-continuous electrograms (EGMs) on 1-2 adjacent bipoles.

\section{METHODS}

The single-center CHAOS study prospectively included all patients scheduled for reentrant AT ablation from May 2017 to December 2019, excluding patients diagnosed with CTI-dependent atrial flutter, in which the tachycardia circuit was deemed non-mappable due to continuous circuit modification or conversion to atrial fibrillation. All patients had pre-procedural documentation of reentrant AT on the surface ECG based on: 1) the presence of continuous atrial activity on the surface ECG, or: 2) in patients with focal AT pattern, the arrhythmia behavior (stable cycle length without modification at onset or end) and patient characteristics (diseased atria). ${ }^{13}$ Patients could present to the ablation procedure in sinus rhythm, AT or AF.

Written informed consent was obtained before the procedures and patient data were collected in a dedicated database. The study complied with the Declaration of Helsinki and received prior approval by the ethics committee of our institution.

\section{Procedures}

Procedures were preferably performed under general anesthesia, or conscious sedation if general anesthesia was not available. Antiarrhythmic medications were neither discontinued prior to ablation, nor administered during the procedures. After achieving echography-guided femoral vein access, a 24-pole diagnostic catheter (Woven Orbiter, Boston Scientific Inc.) was placed around the tricuspid annulus with its distal part into the coronary sinus. If the initial rhythm was AT, entrainment from both right and left atria (via coronary sinus) was used to define AT origin. If the patient was in sinus rhythm, atrial programmed stimulation with ramps was first used to induce AT. If the left atrium (LA) was intended to map, transseptal puncture with a conventional long sheath (SL1, Abbott Medical Inc., Chicago, IL) was performed and intravenous heparin was administered to achieve a target activated clotting time of 350-400 seconds. Steerable sheaths (Agilis, Abbott Medical Inc.) were only used to improve catheter manipulation in selected difficult cases.

Patients were included if AF was induced, or conversion from AT to AF (or continuous AT circuit changes, considered equivalent to AF) happened during the procedure, and no spontaneous re-conversion to a stable AT occurred during the following 15 minutes. Also, patients with AF as initial rhythm were included.

\section{Mapping protocol and rotor identification}

Mapping was performed using conventional high-density electroanatomical mapping catheters (IntellaMap ORION, Boston Scientific Inc.; PentaRay NAV, Biosense Webster Inc.; or Advisor HD Grid, Abbott Medical, Inc.) and their respective mapping system (Rhythmia, Carto3 or Ensite Precision). Bipolar voltage maps were created, with the threshold for dense scar set bellow $0.03 \mathrm{mV}$ in all navigation systems, in order to allow annotation of low-voltage signals.

For patients with AT as initial rhythm, or AT induced from sinus rhythm, and posterior destabilization, mapping was initiated within the right atrium (RA) or LA, depending on the suspected origin of the AT according to initial entrainment. If destabilization occurred before or during entrainment, mapping was started within the atrium in which initial disorganization of electrical signals during AT presumably led to AF. For patients with AF as initial rhythm, mapping was initiated in the atrium with faster cycle length according to the Orbiter catheter signals. If rotors were identified in the initially mapped atrium, rotor ablation was performed; if rotors were not present, or rotor ablation was not successful to convert AF into AT or sinus rhythm, the other atrium was then mapped for rotor identification. 
Rotors were subjectively identified as fractionated continuous (or quasi-continuous) bipolar EGMs on 1-2 adjacent bipoles of the mapping catheter, using a digital recorder (Bard LabSystem Pro) at $200 \mathrm{~mm} / \mathrm{s}$ speed (Figure 1, panel A). Filters for bipolar signals were set at 30 and $250 \mathrm{~Hz}$, with notch filter. When such EGMs were identified, the mapping catheter was kept still for 10 seconds to confirm temporal stability of the rotor, which was then annotated with a manual marker deployed on an electroanatomical bipolar voltage map. After mapping was complete, the mapping catheter was repositioned in sites with rotors to confirm temporal permanence before ablation. Temporally unstable rotors were neither annotated nor targeted for ablation.

If rotors were absent in both atria, or rotor ablation was unsuccessful to stabilize or terminate AF, sites with STD (i.e. all the AF cycle length comprised within the different bipoles of the mapping catheters) plus non-continuous fragmentation on single bipoles, arbitrarily defined as continuous bipolar EGMs with $>4$ deflections and total duration $>70 \mathrm{~ms}$, were manually annotated and targeted for ablation (Figure 1, panel B). At least 10 seconds of temporal stability was also required for these sites.

\section{Ablation protocol}

Radiofrequency ablation was performed using open-tip irrigated catheters (IntellaNav MIFI, Boston Scientific Inc.; Thermocool SmartTouch, Biosense Webster Inc.; TactiCath, Abbott Medical Inc.; or TactiCath, Sensor Enabled, Abbott Medical Inc.). A power of 30-35 W was used for posterior wall lesions, 35-40 W for anterior or free wall lesions, and 25-30 $\mathrm{W}$ inside the coronary sinus.

First, focal ablation of the identified rotors were performed with 1-4 adjacent lesions. If rotor ablation was unsuccessful, sites with STD were targeted using the same focal approach.

Rotor ablation success was defined, for each patient, as conversion to sinus rhythm or a stable AT using the aforementioned strategy. If rotors were present within the pulmonary veins antra, circumferential pulmonary vein isolation of that vein or pair of veins was performed including the rotor within the line. If rotor ablation was performed $<1 \mathrm{~cm}$ from a scar or another radiofrequency application, an ablation line between them was performed. If rotor ablation was not successful, electrical cardioversion and empirical pulmonary vein isolation plus CTI ablation was performed.

All stable ATs were mapped using local activation time mapping, propagation mapping and entrainment, and subsequently ablated (focal ablation for small reentries or focal ATs; lines for macroreentries). In the case of conversion to another AT, the new AT was mapped and ablated. After conversion to sinus rhythm, bidirectional block at the ablation lines was checked with differential pacing or with activation mapping, and absence of capture at focal ablation sites was tested. If the patient had undergone previous ablation procedures, bidirectional block of the previously performed lines was checked, and ablation was performed if gaps were present. Pulmonary vein isolation was not performed in all patients, but it was routinely completed in those with previously documented atrial fibrillation.

Finally, programmed atrial stimulation was used to test arrhythmia inducibility; if other sustained ATs were induced, they were mapped and ablated. Procedural success was defined as the successful ablation of all inducible ATs, without requiring electrical cardioversion, with final sinus rhythm and non-inducibility at the end of the procedure.

\section{Follow-up}

Patients were followed up with clinical visits and 24-hour Holter monitoring at 3,6 and 12 months. Any arrhythmia lasting $>30$ seconds, according to patients' symptoms or documented on Holter monitoring, was considered a recurrence. A blanking period of 3 months, in which recurrences were mostly treated with electrical cardioversion, was considered. After the 3-month blanking period, paroxysmal and well tolerated short episodes of tachycardia were managed with medication or a wait-and-see strategy. Persistent or bad tolerated episodes were treated with repeat ablation, electrical cardioversion or atrioventricular node ablation and pacemaker implant, depending on the presumed risk of posterior recurrences according to the grade of atrial disease. 
In patients taking rhythm control drugs before the procedure, these were kept during the blanking period, and afterwards discontinued if no recurrences had occurred; these drugs might be continued up to 3 additional months (until the 6-month follow-up visit) at the discretion of the attending physician.

\section{Statistical analysis}

Categorical variables are described as number (percentage) and were compared with the $\chi^{2}$ or the Fisher's exact tests, as appropriate. Continuous variables are described as mean $\pm \mathrm{SD}$ for variables with normal distributions or as median [interquartile range] for variables not normally distributed. The KolmogorovSmirnov test was used to assess normality in continuous variables. Comparisons among normal continuous variables were made using Student's t tests (normal variables) or Mann-Whitney U tests (for variables not normally distributed). Bilateral p values $<0.05$ were considered statistically significant. For survival analysis (recurrence of atrial arrhythmias), the Kaplan-Meier method was used. Statistical analysis was performed using SPSS Statistics Base version 22.0 package (IBM Inc., Armonk, NY).

\section{RESULTS}

From May 2017 to December 2019, 97 patients were scheduled for reentrant AT ablation, excluding CTIdependent atrial flutter. Of these, 18 patients (18.6\%) presented non-mappable circuits and were included (Table 1). 7 Patients $(39 \%)$ were $>75$ years of age and 4 patients $(22 \%)$ were $>80$ years of age. 7 Patients (39\%) had severe LA dilation. Mean procedural time was $265 \pm 67$ minutes and mean fluoroscopy use, expressed as dose-product area (PDA), was $28499 \pm 10212 \mathrm{mGy} \cdot \mathrm{cm}^{2}$. Of note, only 5 patients were on rhythm control drugs (flecainide, $\mathrm{n}=2$; propafenone, $\mathrm{n}=1$; sotalol, $\mathrm{n}=1$; and amiodarone, $\mathrm{n}=1$ ) before the index procedure.

Included patients (with non-mappable circuits) had less enlarged left atria than those with mappable circuits.

\section{Mapping and rotor ablation}

Among the 18 included patients, $14(77.7 \%)$ presented to the ablation procedure in sinus rhythm; in 12 patients, an AT was induced but was considered not mappable due to conversion to $\mathrm{AF}(\mathrm{n}=10)$ or continuous circuit modification $(\mathrm{n}=2)$; in the other 2 patients, programmed atrial stimulation directly induced AF. 3 Patients $(16.7 \%)$ presented in AT; in 2 of them, conversion to AF during mapping occurred; in the other patient, after successful ablation of the index AT, programmed atrial stimulation induced AF. 1 Patient (5.6\%) presented in $\mathrm{AF}$.

Mapping was performed with PentaRay NAV catheter (Carto3) in 5 patients (28\%), with IntellaMap ORION (Rhythmia) in 11 patients (61\%), and with Advisor HD Grid (Ensite Precision) in 2 patients (11\%). Contact force-sensing catheters were used for ablation in 6 patients (33.3\%). In 9 patients (50\%), rotor mapping and ablation was performed only in the LA; in 1 patient, only in the RA; in the other 8 patients (44.4\%), both atria were mapped. Detailed rotor mapping and ablation approach is showed in Figure 2.

Rotors, defined as sites with fractionated quasi-continuous signals on 1-2 adjacent bipoles of the mapping catheter, were found in 13 patients $(72 \%)$ (median 2 [1-3] rotors per patient) (Figure 3); all detected rotors showed temporal permanence after mapping and were target of ablation. Focal rotor ablation was effective in 12 of these patients (92\%); in the other patient, after unsuccessful rotor ablation, 2 sites with STD and non-continuous fragmentation were detected and successfully ablated to stabilize AF into reentrant AT. In 1 patient without detectable rotors, spontaneous stabilization of AF into reentrant AT happened during mapping, and AT ablation could be successfully performed. In the other 4 patients without rotors, sites with STD and non-continuous fragmentation were detected $(2,3,4$ and 6 sites in each patient) (Figure 4); ablation of these sites resulted in arrhythmia stabilization into AT in 3 patients (75\%); the other patient received electrical cardioversion. Figure 5 shows location of the detected rotors and sites with STD and non-continuous fragmentation; globally $44 \%$ were related with the pulmonary veins antra.

\section{Ablation and procedural success}


Globally, and excluding the patient in which spontaneous conversion of AF into AT occurred, ablation of rotors or sites with STD was effective in 16/17 patients (rotor ablation success : $94.1 \%$ ); in 6 patients, conversion to sinus rhythm occurred, whereas in the other 10 patients, ablation resulted in stable AT. Table 2 shows details about the ATs induced in each patient and the ablation strategy performed; 19 macroreentries and 10 microreentries were found; 5 focal ATs appeared. Considering previous ablations and the index procedure, 11 patients (61\%) had pulmonary vein isolation, and 15 patients (83\%) had CTI ablation.

Procedural success was achieved in $16 / 18$ patients (88.9\%). The 2 patients with failed procedure were: the one in which rotor ablation was not effective and electrical cardioversion was needed (empirical pulmonary vein isolation plus CTI ablation was performed); and a patient with successful rotor ablation and subsequent ablation of 2 reentrant ATs, but inducibility of another AT that was not ablated afterwards (it was terminated with entrainment maneuvers and no re-inducibility was attempted). There were no procedural complications. In patients with mappable reentrant ATs, the rate of procedural success $(92.4 \%$; $=0.639)$ and procedural complications $(11.4 \% ; \mathrm{p}=0.200)$ were similar.

\section{Clinical results}

After a mean follow-up of $19.3 \pm 15.3$ months, and excluding a 3-month blanking period, mean survival free from atrial arrhythmias was $22.1 \pm 3.5$ months (95\%CI: $15.4-28.9$ months). Clinical and procedural variables of patients with and without recurrences of atrial arrhythmias are shown in Table 3. No statistical comparisons were made due to the limited sample size.

5 Patients had arrhythmia recurrences during the blanking period; in 3 of them, electrical cardioversion was performed, with 1 recurrence after the blanking period; in the other 2 patients, rhythm control strategy was abandoned, and atrioventricular node ablation plus pacemaker implant was needed. 8 Patients had arrhythmia recurrencesafter the blanking period (including the 2 patients in whom rhythm control was stopped): 5 with AT and 3 with AF; 3 reablation procedures were performed; 2 showed a different reentrant AT, and 1 showed a gap-related AT. Of the 15 patients with follow-up $>1$ year, 10 (66.7\%) were free from atrial arrhythmias at a 12-month follow-up.

Mean survival free from atrial arrhythmias in patients with ablation of mappable reentrant ATs during the same period (24.9 \pm 2.1 months; 95\%CI: 20.7-29.2 months) was similar ( $\mathrm{p}=0.740)$ (Figure 6 ), as well as one-year freedom from atrial arrhythmias $(65.8 \%, \mathrm{p}=0.946)$.

\section{DISCUSSION}

We have tested an ablation strategy for unstable reentrant ATs based on focal rotor ablation. To our knowledge, this is the first study that uses driver ablation in patients with reentrant ATs in order to stabilize unstable circuits. Most patients showed rotors or sites with STD plus non-continuous fractionation that could be ablated to achieve AT stabilization or termination with high success.

Ablation of reentrant ATs, excluding CTI-dependent atrial flutter, has shown limited one-year freedom from atrial arrhythmias in recent reports (51\%-77\%)., ${ }^{1,5-7}$ Moreover, acute procedural success, defined as AT termination into sinus rhythm or conversion to another AT, is not achieved in approximately $10-15 \%$ of cases. $^{1,5-7}$ We have obtained, in a cohort of patients classically excluded from other series and considered as especially complex, similar rates of procedural success (88.9\%) and one-year freedom from atrial arrhythmias (66.7\%). In patients with mappable reentrant ATs ablated in the same period of time in our Centre, results were also comparable. Interestingly, included patients had less dilated atria than these patients with mappable reentrant ATs; maybe, in more enlarged atrium, with more dense-scarred tissue and less conduction speed, reentrant circuits are more prone to stabilize.

Rotor identification has to date been based mostly on the use of dedicated catheters and/or software that imply additional costs and time consumption during ablation procedures. ${ }^{14-17}$ On the contrary, STD analysis as a tool to find rotational activity can be performed with conventional high-density mapping catheters and is subjectively performed by operators according to visually detectable electrical patterns which show very high $(94.3 \%)$ interobserver concordance. ${ }^{11}$ Of these patterns, the most specific is the finding of a 
fractionated continuous signal in a single bipole of the mapping catheter, present in almost all regions with dispersion and in almost no regions without dispersion. ${ }^{11}$ We hypothesize that fractionated continuous (or quasi-continuous) activity should be visualized within the majority of rotor cores on bipolar signals, as true functional microreentries (Figure 1, panel A); in fact, fragmentation to consider 'conventional' anatomical microreentry has been defined as that comprising $>75 \%$ of the tachycardia cycle length..$^{9,18}$ In peripheral regions, however, we believe that spatiotemporal distribution of signals (i.e. all the AF cycle length comprised within the different bipoles of the mapping catheter), which may exhibit some fractionation but not on a continuous manner, could be the most frequent pattern. Besides, finding the rotor pivoting point (i.e. core) would allow focal ablation, which should be sufficient to stop rotational activity without the need of performing more extensive ablation of all the rotor 'region'. For these reasons, we decided to use the finding of fractionated quasi-continuous signals on a limited number of adjacent bipoles of the mapping catheter as our definition of rotor. This definition, whether representing or not the true core of rotors, allowed focal ablation with high efficacy in our series.

Another pattern, electrical STD plus non-continuous fragmentation on single bipoles, was used as the marker of rotational activity for patients in which the former pattern could not be found. We hypothesize that, if the rotor core slightly travels with a rotational pattern, fractionated but not continuous activity could be visualized with single bipoles of the mapping catheter located within the travelling trajectory of the rotor core (Figure 1, panel B).

In patients with $\mathrm{AF}$, conversion rates with driver ablation ranges between one third ${ }^{19}$ and two thirds of cases in most reports ${ }^{17}$, with a pooled success rate of $39.6 \%$ in a recent meta-analysis, ${ }^{10}$ although higher efficacies up to $95 \%$ have been reported. ${ }^{11}$ The high conversion rate observed in our series could be related to the nature of the arrhythmia; in the continuum between stable reentrant AT and AF, unstable reentrant ATs might exhibit atrial conduction properties less prone to chaotic conduction than AF, and, hence, easier to stabilize through ablation. Also, the mean number of rotors we found in our cohort $(2.0 \pm 1.23$ rotors per patient) is in the low range of reported data on AF driver ablation (which ranges from $1.8 \pm 1.23$ to $5 \pm 1.5$ drivers per patient $)^{11,20}$, although no clear relationship between the number of drivers and ablation success to convert AF seems to exist. ${ }^{10}$ The main location of rotors was the pulmonary vein antra (42\%), which is a common place for AF drivers. In a study that specifically addressed locations where AF termination was achieved in a cohort of AF patients ${ }^{16}, 27.5 \%$ of terminations occurred ablating within the pulmonary vein antra, and in $91 \%$ of these locations a rotor was detected.

Another reason that may justify our rotor ablation success rate is a higher short-term spatiotemporal stability of rotors in the context of unstable AT than in AF. Although this affirmation is hypothetical, all rotors that were found through initial mapping in our cohort persisted in the same location when mapping was complete several minutes afterwards. The 10-seconds criterion to determine temporal stability of rotors in our series was arbitrarily set between reported time criteria, which ranges between $2.5 \mathrm{~s}$ and $30 \mathrm{~s}$ in most series. ${ }^{11,21}$ However, spatiotemporal stability of drivers in the medium or long term in AF patients has not been demonstrated, ${ }^{22}$ which might account at least partially (along with atrial disease progression) for arrhythmia recurrences after driver ablation both in AF and unstable AT patients. Indeed, 37.5\% of recurrences in our cohort were AF instead of AT.

\section{Study limitations}

The main limitation of this study is the limited sample size, due to the fact that it was a single-center study and patients with non-mappable reentrant ATs scheduled for ablation are not frequent. Also, as this was an observational study, no comparisons were made with other ablation strategies (e.g. substrate ablation), which may have been also effective.

\section{CONCLUSION}

Most non-mappable reentrant ATs show detectable rotors, identified as sites with single-bipole fractionated quasi-continuous signals, or STD with non-continuous fractionation. Ablation of these sites is highly effective to stabilize the AT or convert it into sinus rhythm. 


\section{REFERENCES}

1. Anter E, McElderry TH, Contreras-Valdes FM, Li J, Tung P, Leshem E, Haffajee CI, Nakagawa H, Josephson ME. Evaluation of a novel high-resolution mapping technology for ablation of recurrent scar-related atrial tachycardias. Heart Rhythm. 2016;13:2048-2055.

2. Patel AM, d'Avila A, Neuzil P, Kim SJ, Mela T, Singh JP, Ruskin JN, Reddy VY. Atrial tachycardia after ablation of persistent atrial fibrillation: identification of the critical isthmus with a combination of multielectrode activation mapping and targeted entrainment mapping.Circ Arrhythm Electrophysiol . 2008;12:1047-1049.

3. Waldo AL. Pathogenesis of atrial flutter. J Cardiovasc Electrophysiol . 1998;9:S18-25.

4. Nakagawa H, Shah N, Matsudaira K, Overholt E, Chandrasekaran K, Beckman KJ, Spector P, Calame JD, Rao A, Hasdemir C, Otomo K, Wang Z, Lazzara R, Jackman WM. Characterization of reentrant circuit in macroreentrant right atrial tachycardia after surgical repair of congenital heart disease: isolated channels between scars allow "focal" ablation. Circulation . 2001;103:699-709.

5. Coffey JO, d'Avila A, Dukkipati S, Danik SB, Gangireddy SR, Koruth JS, Miller MA, Sager SJ, Eggert CA, Reddy VY. Catheter ablation of scar-related atypical atrial flutter. Europace. 2013;15:414-419.

6. Ammar S, Luik A, Hessling G, Bruhm A, Reents T, Semmler V, Buiatti A, Kathan S, Hofmann M, Kolb C, Schmitt C, Deisenhofer I. Ablation of perimitral flutter: acute and long-term success of the modified anterior line. Europace. 2015;17:447-452.

7. Winkle RA, Moskovitz R, Mead RH, Engel G, Kong MH, Fleming W, Patrawala RA. Ablation of atypical atrial flutters using ultra high density-activation sequence mapping. J Interv Card Electrophysiol . 2017;48:177-184.

8. Takigawa M, Derval N, Frontera A, Martin R, Yamashita S, Cheniti G, Vlachos K, Thompson N, Kitamura T, Wolf M, Massoullie G, Martin CA, Al-Jefairi N, Amraoui S, Duchateau J, Klotz N, Pambrun T, Denis A, Sacher F, Cochet H, Hocini M, Haïssaguerre M, Jais P. Revisiting anatomic macroreentrant tachycardia after atrial fibrillation ablation using ultrahigh-resolution mapping: implications for ablation. Heart Rhythm . 2018;15:326-333.

9. Strisciuglio T, Vandersickel N, Lorenzo G, Van Nieuwenhuyse E, El Haddad M, De Pooter J, Kyriakopoulou M, Almorad A, Lycke M, Vandekerckhove Y, Tavernier R, Duytschaever M, Knecht S. Prospective evaluation of entrainment mapping as an adjunct to new-generation high-density activation mapping systems of left atrial tachycardias. Heart Rhythm . 2020;17:211-219.

10. Baykaner T, Rogers AJ, Meckler GL, Zaman J, Navara R, Rodrigo M, Alhusseini M, Kowalewski CAB, Viswanathan MN, Narayan SM, Clopton P, Wang PJ, Heidenreich PA. Clinical implications of ablation of drivers for atrial fibrillation: a systematic review and meta-analysis. Circ Arrhythm Electrophysiol . 2018;11:e006119.

11. Seitz J, Bars C, Théodore G, Beurtheret S, Lellouche N, Bremondy M, Ferracci A, Faure J, Penaranda G, Yamazaki M, Avula UM, Curel L, Siame S, Berenfeld O, Pisapia A, Kalifa J. AF ablation guided by spatiotemporal electrogram dispersion without pulmonary vein isolation: a wholly patient-tailored approach. J Am Coll Cardiol . 2017;69:303-321.

12. Waldo AL, Feld GK. Inter-relationships of atrial fibrillation and atrial flutter J Am Coll Cardiol. 2008;51:779-786.

13. Saoudi N, Cosio F, Waldo A, Chen S-A, Iesaka Y, Lesh M, Saksena S, Salerno J, Schoels W. Classification of atrial flutter and regular atrial tachycardia according to electrophysiologic mechanism and anatomic bases: a statement from a joint expert group from the Working Group of Arrhythmias of the European Society of Cardiology and the North American Society of Pacing and Electrophysiology. J Cardiovasc Electrophysiol. 2001;12:852-866. 
14. Narayan SM, Krummen DE, Shivkumar K, Clopton P, Rappel WJ, Miller JM. Treatment of atrial fibrillation by the ablation of localized sources: CONFIRM (Conventional Ablation for Atrial Fibrillation With or Without Focal Impulse and Rotor Modulation) trial. J Am Coll Cardiol . 2012;60:628-636.

15. Calvo D, Rubín J, Pérez D, Morís C. Ablation of rotor domains effectively modulates dynamics of human long-standing persistent atrial fibrillation. Circ Arrhythm Electrophysiol . 2017;10:e005740.

16. Navara R, Leef G, Shenasa F, Kowalewski C, Rogers AJ, Meckler G, Zaman JAB, Baykaner T, Park S, Turakhia MP, Zei P, Viswanathan M, Wang PJ, Narayan SM. Independent mapping methods reveal rotational activation near pulmonary veins where atrial fibrillation terminates before pulmonary vein isolation. J Cardiovasc Electrophysiol . 2018;29:687-695.

17. Quintanilla JG, Alfonso-Almazán JM, Pérez-Castellano N, Pandit SV, Jalife J, Pérez-Villacastín J, Filgueiras-Rama D. Instantaneous amplitude and frequency modulations detect the footprint of rotational activity and reveal stable driver regions as targets for persistent atrial fibrillation ablation. Circ Res . 2019;125:609-627.

18. Laţcu DG, Bun SS, Viera F, Delassi T, El Jamili M, Al Amoura A, Saoudi N. Selection of critical isthmus in scar-related atrial tachycardia using a new automated ultrahigh resolution mapping system.Circ Arrhythm Electrophysiol. 2017;10:e004510.

19. Atienza F, Almendral J, Ormaetxe JM, Moya A, Martínez-Alday JD, Hernández-Madrid A, Castellanos E, Arribas F, Arias MÁ, Tercedor L, Peinado R, Arcocha MF, Ortiz M, Martínez-Alzamora N, Arenal A, Fernández-Avilés F, Jalife J; RADAR-AF Investigators. Comparison of radiofrequency catheter ablation of drivers and circumferential pulmonary vein isolation in atrial fibrillation: a noninferiority randomized multicenter RADAR-AF trial. J Am Coll Cardiol . 2014;64:2455-2467.

20. Steinberg JS, Shah Y, Bhatt A, Sichrovsky T, Arshad A, Hansinger E, Musat D. Focal impulse and rotor modulation: acute procedural observations and extended clinical follow-up. Heart Rhythm . 2017;14:192-197.

21. Honarbakhsh S, Schilling RJ, Finlay M, Keating E, Hunter RJ. Prospective STAR-guided ablation in persistent atrial fibrillation using sequential mapping with multipolar catheters. Circ Arrhythm Electrophysiol . 2020;13:e008824.

22. Jarman JW, Wong T, Kojodjojo P, Spohr H, Davies JE, Roughton M, Francis DP, Kanagaratnam P, Markides V, Davies DW, Peters NS. Spatiotemporal behaviour of high dominant frequency during paroxysmal and persistent atrial fibrillation in the human left atrium. Circ Arrhythm Electrophysiol . 2012;5:650-658.

\section{FIGURES}

\section{FIGURE 1}



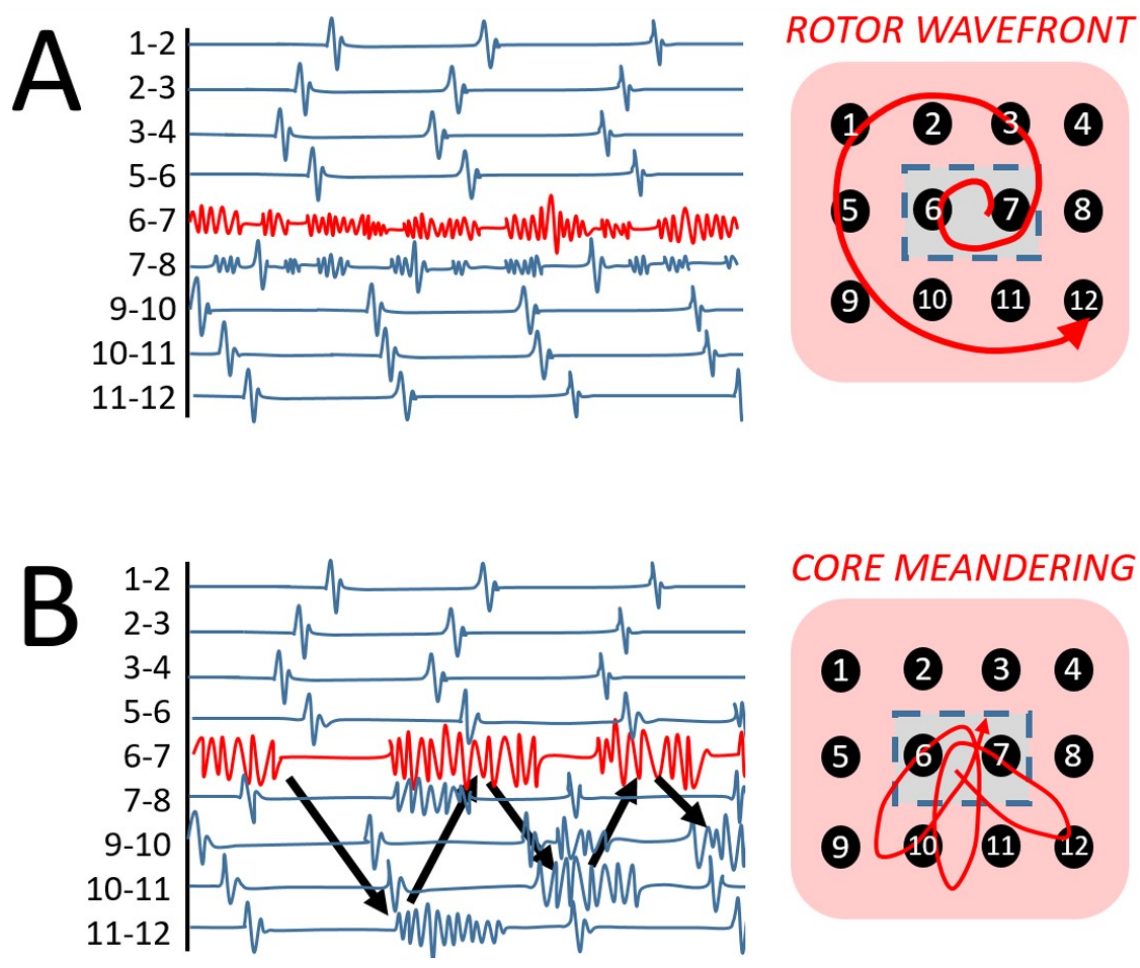

Figure 1. Schematic rationale of rotor detection using a hypothetical 12-pole mapping catheter. (A) A stable rotor would theoretically show fractionated quasi-continuous electrograms on the bipoles placed on the rotor core (6-7), as the mapping area of that bipoles would detect electrical activity during almost all the cycle length. Other bipoles may (or may not) show some degree of fractionation. Red arrow represents rotor spiral wavefront. (B) If the rotor core meanders around the neighboring tissue, the fractionation would move between different bipoles through time, resulting in non-continuous fractionation. Red arrow represents meandering of the rotor core.

FIGURE 2 


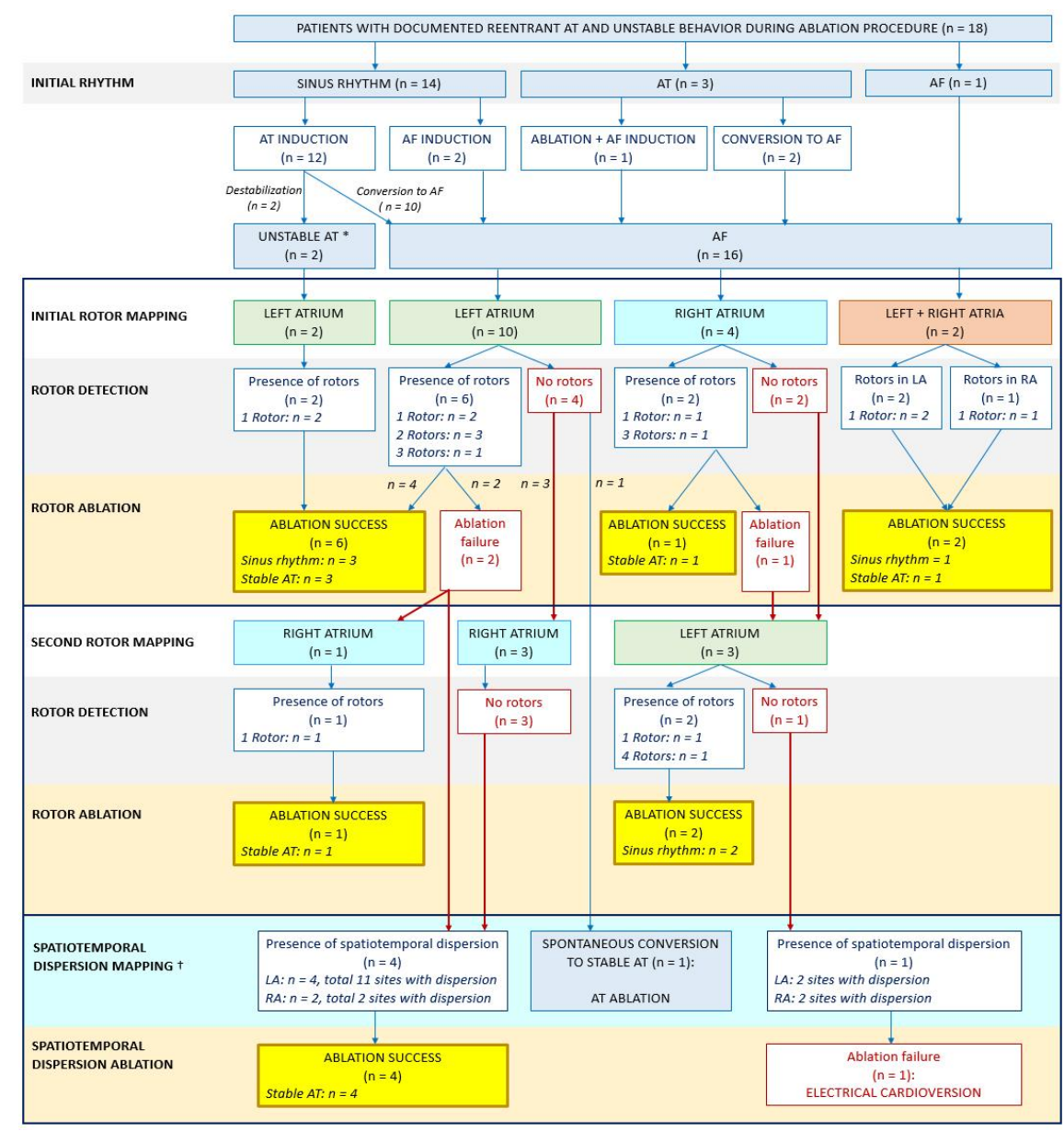

Figure 2. Detailed mapping and ablation approach. AF = atrial fibrillation; $\mathrm{AT}=$ atrial tachycardia.

* Unstable AT is defined as having continuous circuit modification.

+ Spatiotemporal dispersion mapping was biatrial in all patients but 1, in which after failed rotor ablation in the LA, sites with spatiotemporal dispersion were successfully targeted in the LA before considering RA rotor mapping.

FIGURE 3 

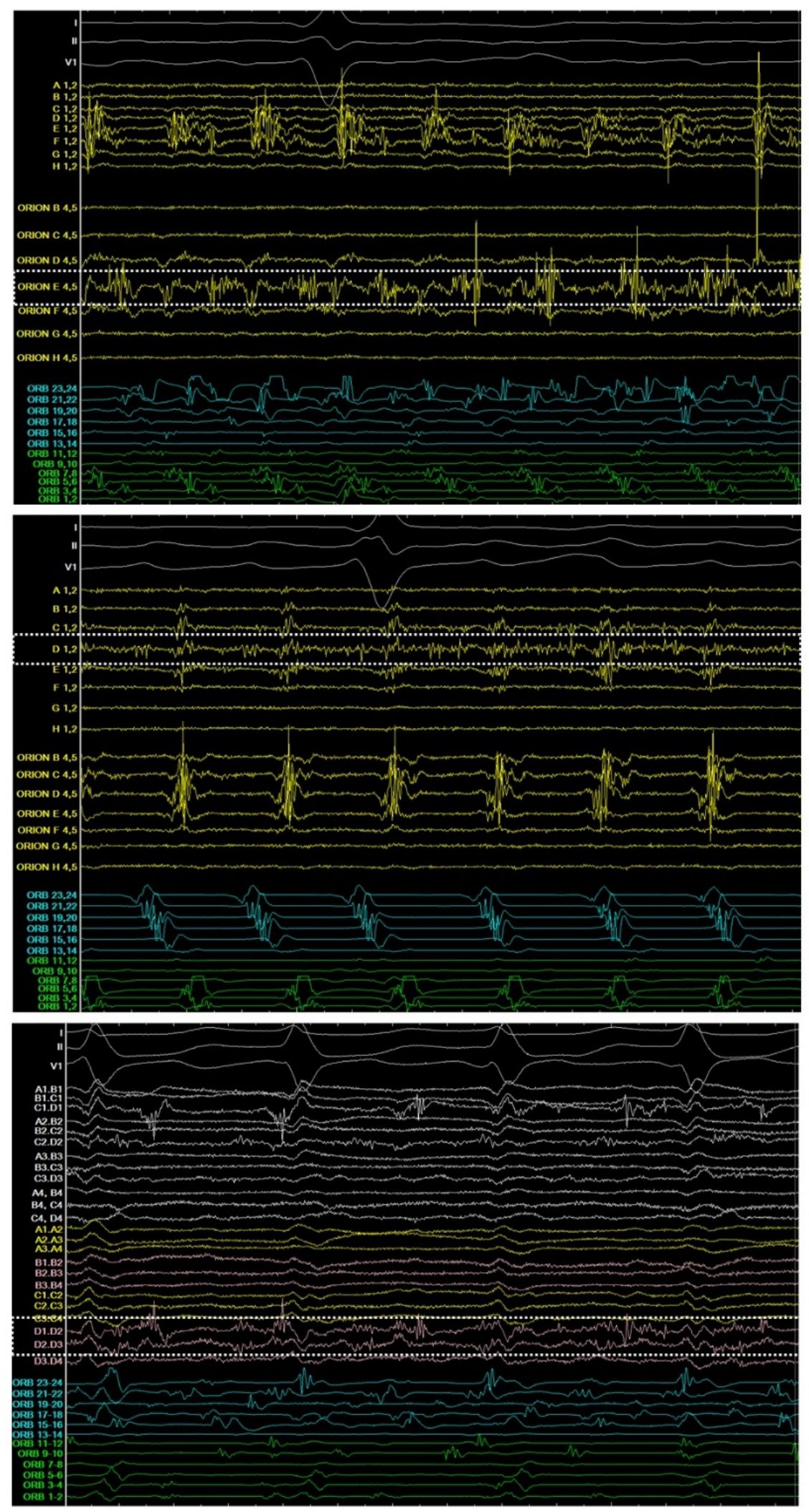
Figure 3 . Representative examples of rotors (dotted lines). Upper panel and middle panel: IntellaMap ORION catheter; rotors detected in a single bipole. Lower panel: Advisor HD Grid catheter; rotor detected in 2 adjacent bipoles (D1-D2 and D2-D3). Note the low voltage of electrical signals in the middle and lower panel. Paper speed: $200 \mathrm{~mm} / \mathrm{s}$. ORB $=$ Woven Orbiter catheter; blue bipoles around tricuspid annulus and green bipoles into the coronary sinus.

\section{FIGURE 4}



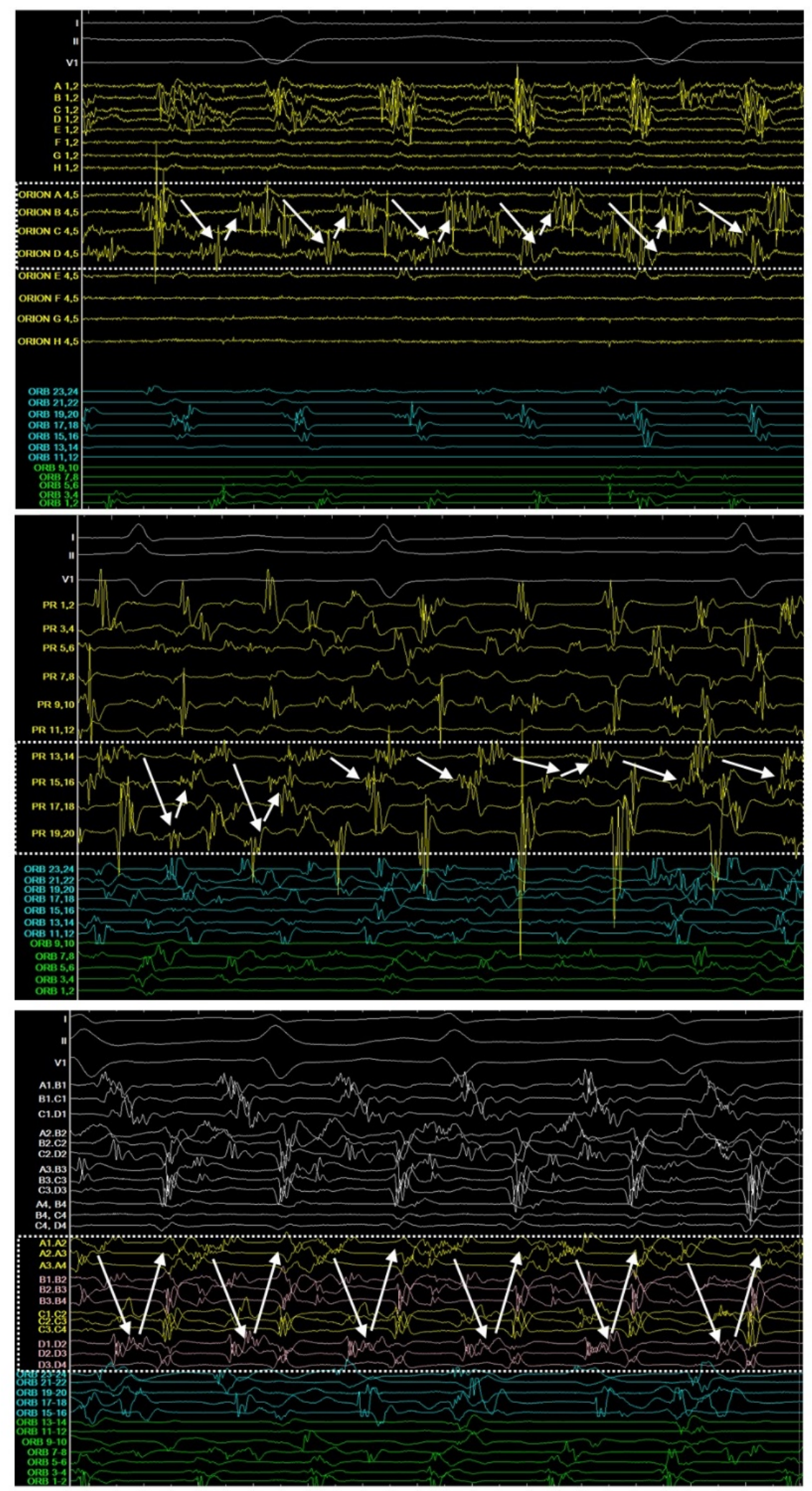
Figure 4. Representative examples of sites with spatiotemporal dispersion and non-continuous fractionation (dotted lines). Arrows represent hypothetical trajectory of a meandering rotor core. Upper panel: IntellaMap ORION catheter. Middle panel: PentaRay NAV catheter (PR). Lower panel: Advisor HD Grid catheter. Paper speed: $200 \mathrm{~mm} / \mathrm{s}$. ORB = Woven Orbiter catheter; blue bipoles around tricuspid annulus and green bipoles into the coronary sinus.

\section{FIGURE 5}

$$
\text { ROTORS IN THE RA, } n=6 \text {. }
$$

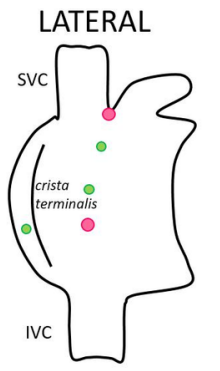

SEPTAL

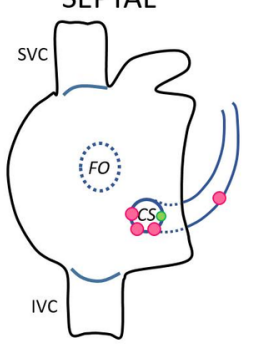

Sites with spatiotemporal dispersion and non-continuous fractionation, $n=17$.
ROTORS IN THE LA, $n=20$.

POSTERIOR
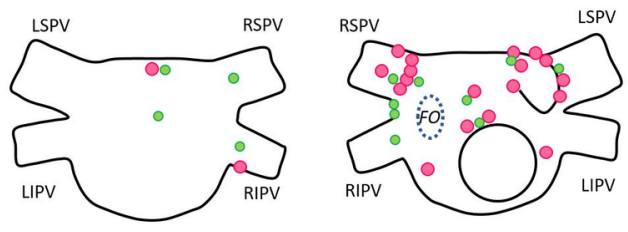

Figure 5. Location of rotors (pink dots) and sites with spatiotemporal dispersion and non-continuous fragmented EGMs (green dots). 11 Rotors (42\%) were related to the antra of the pulmonary veins, especially the anterior aspect of the right superior pulmonary vein $(\mathrm{n}=6)$ and the ridge between the left atrial appendage and the left superior pulmonary vein $(n=4)$. CS = coronary sinus; FO = foramen ovale; IVC $=$ inferior vena cava; LIPV $=$ left inferior pulmonary vein; LSPV = left superior pulmonary vein; RIPV $=$ right inferior pulmonary vein; RSPV = right superior pulmonary vein; SVC = superior vena cava.

\section{FIGURE 6}




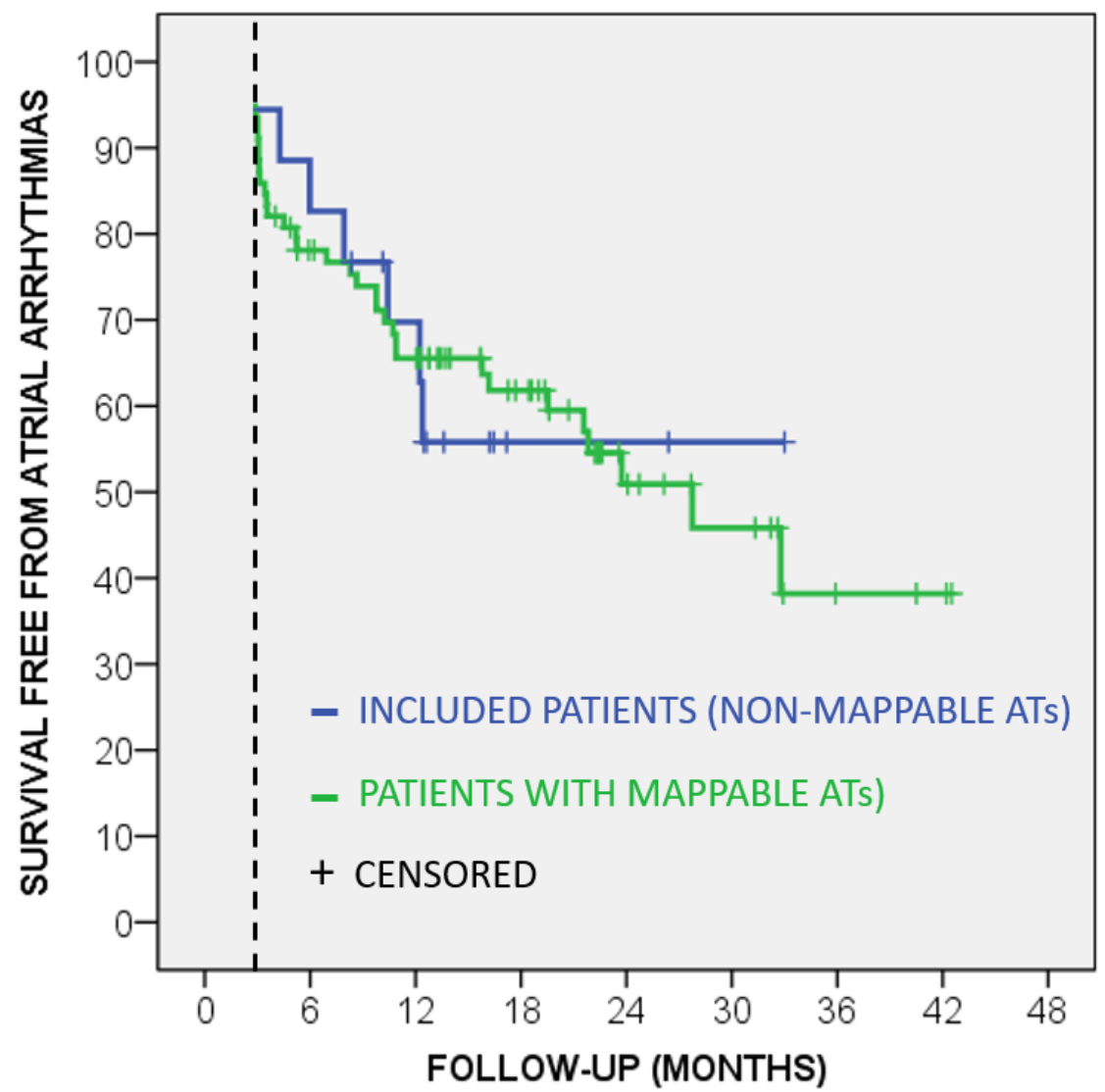

Figure 6. Estimated survival free from atrial arrhythmias, excluding a 3-month blanking period, in included patients and patients with ablation of mappable reentrant ATs during the same period. AT $=$ atrial tachycardia.

\section{TABLES}

Table 1. Comparison between clinical variables of the included patients and patients with mappable reentrant ATs scheduled for ablation in our Center during the inclusion period.

\begin{tabular}{|c|c|c|c|}
\hline & $\begin{array}{l}\text { Included patients } \\
\text { (non-mappable ATs) (n } \\
=18)\end{array}$ & $\begin{array}{l}\text { Other patients } \\
\text { (mappable ATs) }(\mathrm{n}=79)\end{array}$ & $\mathrm{p}$ \\
\hline Age (years) & $72.1 \pm 8.9$ & $70.5 \pm 9.0$ & 0.514 \\
\hline Females $(\%)$ & $9(50 \%)$ & $45(57 \%)$ & 0.610 \\
\hline $\begin{array}{l}\text { Left ventricular } \\
\text { ejection fraction }(\%)\end{array}$ & $58[54-61]$ & $64[55-71]$ & 0.023 \\
\hline $\begin{array}{l}\text { Indexed left atrial } \\
\text { volume }\left(\mathrm{ml} / \mathrm{m}^{2}\right)\end{array}$ & $36.6 \pm 11.9$ & $45.8 \pm 17.4$ & 0.038 \\
\hline $\begin{array}{l}\text { Significant structural } \\
\text { cardiopathy }\end{array}$ & $9(50 \%)$ & $43(54 \%)$ & 0.797 \\
\hline $\begin{array}{l}\text { Previous atrial } \\
\text { fibrillation }\end{array}$ & $11(61 \%)$ & $38(48 \%)$ & 0.435 \\
\hline
\end{tabular}




\begin{tabular}{llll}
\hline & $\begin{array}{l}\text { Included patients } \\
\text { (non-mappable ATs) } \\
=18)\end{array}$ & $\begin{array}{l}\text { Other patients } \\
\text { (mappable ATs) }(\mathrm{n}=79)\end{array}$ & $\mathrm{p}$ \\
\hline $\begin{array}{l}\text { Prior ablation procedures } \\
\text { - Pulmonary vein }\end{array}$ & $\begin{array}{l}11(61 \%) 5(28 \%) 6 \\
(33 \%) 3(17 \%)\end{array}$ & $\begin{array}{l}35(44 \%) 18(23 \%) 19 \\
(24 \%) 7(9 \%)\end{array}$ & 0.296 \\
$\begin{array}{l}\text { isolation - CTI ablation - } \\
\text { Other reentrant AT }\end{array}$ & & \\
$\begin{array}{l}\text { ablation } \\
\text { Prior cardiac surgery }\end{array}$ & $4(22 \%)$ & $22(39 \%)$ & 0.772 \\
\hline
\end{tabular}

Data are shown as mean $\pm \mathrm{SD}$, median [interquartile range] or number (percentage), when appropriate. AT $=$ atrial tachycardia. CTI $=$ Cavotricuspid isthmus.

Table 2. Detailed procedural results in each patient.

\begin{tabular}{|c|c|c|c|c|c|}
\hline $\begin{array}{l}\text { Patient } \\
\text { number }\end{array}$ & $\begin{array}{l}\text { Number of } \\
\text { rotors }\end{array}$ & $\begin{array}{l}\text { Effect of rotor } \\
\text { ablation }\end{array}$ & $\begin{array}{l}\text { Number of } \\
\text { sites with STD } \\
*\end{array}$ & $\begin{array}{l}\text { Effect of STD } \\
\text { ablation }\end{array}$ & $\begin{array}{l}\text { ATs ablated } \\
\text { and other } \\
\text { performed } \\
\text { ablations } \\
\text { (apart from } \\
\text { focal ablation } \\
\text { of rotors and } \\
\text { sites with } \\
\text { STD). }\end{array}$ \\
\hline 1 & 2 & $\mathrm{AT}$ & & & $\begin{array}{l}\text { - Small reentry } \\
\text { in the } \\
\text { posterior LA } \\
\text { wall. }\end{array}$ \\
\hline 2 & $0+$ & & & & $\begin{array}{l}\text { - Small reentry } \\
\text { in the RSPV } \\
+ \text { right } \\
\text { superior PVI. }\end{array}$ \\
\hline 3 & 1 & SR & & & $\begin{array}{l}\text { - Typical atrial } \\
\text { flutter. - Right } \\
\text { superior PVI. }\end{array}$ \\
\hline 4 & 1 & $\mathrm{AT}$ & & & $\begin{array}{l}\text { - Typical atrial } \\
\text { flutter. - Focal } \\
\text { AT in the } \\
\text { posterior LA } \\
\text { wall. }\end{array}$ \\
\hline 5 & 3 & $\mathrm{AT}$ & & & $\begin{array}{l}\text { - Perimitral } \\
\text { flutter: ASL. - } \\
\text { Typical atrial } \\
\text { flutter. - SVC } \\
\text { isolation + line } \\
\text { between SVC } \\
\text { and IVC to } \\
\text { connect rotor } \\
\text { ablation sites. }\end{array}$ \\
\hline
\end{tabular}




\begin{tabular}{|c|c|c|c|c|c|}
\hline $\begin{array}{l}\text { Patient } \\
\text { number }\end{array}$ & $\begin{array}{l}\text { Number of } \\
\text { rotors }\end{array}$ & $\begin{array}{l}\text { Effect of rotor } \\
\text { ablation }\end{array}$ & $\begin{array}{l}\text { Number of } \\
\text { sites with STD } \\
*\end{array}$ & $\begin{array}{l}\text { Effect of STD } \\
\text { ablation }\end{array}$ & $\begin{array}{l}\text { ATs ablated } \\
\text { and other } \\
\text { performed } \\
\text { ablations } \\
\text { (apart from } \\
\text { focal ablation } \\
\text { of rotors and } \\
\text { sites with } \\
\text { STD). }\end{array}$ \\
\hline 6 & 2 & $\mathrm{AT}$ & & & $\begin{array}{l}\text { - Small reentry } \\
\text { in the LA roof. - } \\
\text { Perimitral } \\
\text { flutter: MAL. - } \\
\text { Typical atrial } \\
\text { flutter. }\end{array}$ \\
\hline 7 & 2 & SR & & & $\begin{array}{l}\text { - Macroreentry } \\
\text { around the left } \\
\text { pulmonary veins. } \\
\text { - Macroreentry } \\
\text { around the right } \\
\text { pulmonary veins. }\end{array}$ \\
\hline 8 & 5 & $\mathrm{SR}$ & & & $\begin{array}{l}\text { - PVI (rotors } \\
\text { within the } \\
\text { RSPV and } \\
\text { LSPV antra). - } \\
\text { Focal AT in the } \\
\text { crista terminalis. }\end{array}$ \\
\hline 9 & 3 & $\mathrm{AT}$ & & & $\begin{array}{l}\text { - Small reentry } \\
\text { in posteroseptal } \\
\text { mitral annulus. - } \\
\text { Perimitral } \\
\text { flutter: MAL. - } \\
\text { Focal AT from } \\
\text { proximal } \\
\text { coronary sinus. - } \\
\text { PVI (gaps from } \\
\text { previous } \\
\text { procedure). - } \\
\text { Prophylactic } \\
\text { ASL. - CTI } \\
\text { ablation (gap } \\
\text { from previous } \\
\text { procedure). }\end{array}$ \\
\hline
\end{tabular}




\begin{tabular}{|c|c|c|c|c|c|}
\hline $\begin{array}{l}\text { Patient } \\
\text { number }\end{array}$ & $\begin{array}{l}\text { Number of } \\
\text { rotors }\end{array}$ & $\begin{array}{l}\text { Effect of rotor } \\
\text { ablation }\end{array}$ & $\begin{array}{l}\text { Number of } \\
\text { sites with STD } \\
*\end{array}$ & $\begin{array}{l}\text { Effect of STD } \\
\text { ablation }\end{array}$ & $\begin{array}{l}\text { ATs ablated } \\
\text { and other } \\
\text { performed } \\
\text { ablations } \\
\text { (apart from } \\
\text { focal ablation } \\
\text { of rotors and } \\
\text { sites with } \\
\text { STD). }\end{array}$ \\
\hline 10 & 0 & & 2 & $\mathrm{AT}$ & $\begin{array}{l}\text { - Typical atrial } \\
\text { flutter. - } \\
\text { Macroreentry } \\
\text { around the left } \\
\text { pulmonary veins. } \\
\text { - Right inferior } \\
\text { PVI (gap from } \\
\text { previous } \\
\text { procedure). }\end{array}$ \\
\hline 11 & 0 & & 4 & No effect & $\begin{array}{l}\text { - Right PVI } \\
\text { (sites with SPT } \\
\text { within the } \\
\text { RSPV antrum). } \\
\text { Left pulmonary } \\
\text { veins were } \\
\text { spontaneously } \\
\text { isolated. - Line } \\
\text { from anterior } \\
\text { mitral annulus } \\
\text { to scar in the } \\
\text { anterior LA wall } \\
\text { including site } \\
\text { with SPT. - } \\
\text { Empirical CTI } \\
\text { ablation after } \\
\text { electrical } \\
\text { cardioversion. }\end{array}$ \\
\hline 12 & 1 & $\mathrm{SR}$ & & & $\begin{array}{l}\text { - Right PVI } \\
\text { (rotor within the } \\
\text { RSPV antrum). } \\
\text { - Small reentry } \\
\text { in the posterior } \\
\text { LA roof. }\end{array}$ \\
\hline
\end{tabular}




\begin{tabular}{|c|c|c|c|c|c|}
\hline $\begin{array}{l}\text { Patient } \\
\text { number }\end{array}$ & $\begin{array}{l}\text { Number of } \\
\text { rotors }\end{array}$ & $\begin{array}{l}\text { Effect of rotor } \\
\text { ablation }\end{array}$ & $\begin{array}{l}\text { Number of } \\
\text { sites with STD } \\
*\end{array}$ & $\begin{array}{l}\text { Effect of STD } \\
\text { ablation }\end{array}$ & $\begin{array}{l}\text { ATs ablated } \\
\text { and other } \\
\text { performed } \\
\text { ablations } \\
\text { (apart from } \\
\text { focal ablation } \\
\text { of rotors and } \\
\text { sites with } \\
\text { STD). }\end{array}$ \\
\hline 13 & 1 & No effect & 2 & $\mathrm{AT}$ & $\begin{array}{l}\text { - Macroreentry } \\
\text { around the right } \\
\text { pulmonary veins. } \\
\text { - Line from } \\
\text { anterior mitral } \\
\text { annulus to scar } \\
\text { in the anterior } \\
\text { LA wall } \\
\text { including rotor. } \\
\text { - Small reentry } \\
\text { in the interatrial } \\
\text { septum. - } \\
\text { Macroreentry } \\
\text { around the left } \\
\text { pulmonary veins. }\end{array}$ \\
\hline 14 & 0 & & 6 & $\mathrm{AT}$ & $\begin{array}{l}\text { - PVI (sites with } \\
\text { SPT within the } \\
\text { LIPV and RIPV } \\
\text { antra). - Roof } \\
\text { line (site with } \\
\text { SPT in the LA } \\
\text { roof). - Small } \\
\text { reentry in } \\
\text { anterior mitral } \\
\text { annulus. - Small } \\
\text { reentry in } \\
\text { anteroseptal LA } \\
\text { wall. - ASL to } \\
\text { connect } \\
\text { small-reentry } \\
\text { focal ablations. - } \\
\text { Prophylactic } \\
\text { CTI ablation. }\end{array}$ \\
\hline 15 & 3 & $\mathrm{SR}$ & & & $\begin{array}{l}\text { - ASL to connect } \\
2 \text { focal rotors } \\
\text { ablations (PVI } \\
\text { performed in } \\
\text { previous } \\
\text { procedure). - } \\
\text { Prophylactic } \\
\text { CTI ablation. }\end{array}$ \\
\hline
\end{tabular}




\begin{tabular}{|c|c|c|c|c|c|}
\hline $\begin{array}{l}\text { Patient } \\
\text { number }\end{array}$ & $\begin{array}{l}\text { Number of } \\
\text { rotors }\end{array}$ & $\begin{array}{l}\text { Effect of rotor } \\
\text { ablation }\end{array}$ & $\begin{array}{l}\text { Number of } \\
\text { sites with STD } \\
*\end{array}$ & $\begin{array}{l}\text { Effect of STD } \\
\text { ablation }\end{array}$ & $\begin{array}{l}\text { ATs ablated } \\
\text { and other } \\
\text { performed } \\
\text { ablations } \\
\text { (apart from } \\
\text { focal ablation } \\
\text { of rotors and } \\
\text { sites with } \\
\text { STD). }\end{array}$ \\
\hline 16 & 1 & SR & & & $\begin{array}{l}\text { - Perimitral } \\
\text { flutter: ASL. - } \\
\text { Small reentry in } \\
\text { anterior LA wall. } \\
\text { - Left PVI (gaps } \\
\text { from previous } \\
\text { procedure). - } \\
\text { Typical atrial } \\
\text { flutter. }\end{array}$ \\
\hline 17 & 1 & $\mathrm{AT}$ & & & $\begin{array}{l}\text { - Right PVI } \\
\text { (rotor within } \\
\text { RSPV antrum). } \\
\text { - Small reentry } \\
\text { in LSPV: focal } \\
\text { ablation. - } \\
\text { Macroreentry } \\
\text { around the left } \\
\text { pulmonary veins: } \\
\text { left PVI. - } \\
\text { Perimitral } \\
\text { flutter: ASL. - } \\
\text { AVNRT. }\end{array}$ \\
\hline 18 & 0 & & 3 & $\mathrm{AT}$ & $\begin{array}{l}\text { - PVI (sites with } \\
\text { SPT within the } \\
\text { LIPV and RIPV } \\
\text { antra, and in the } \\
\text { ridge). - Reentry } \\
\text { around posterior } \\
\text { LA wall scar. - } \\
\text { Perimitral } \\
\text { flutter: ASL. - } \\
\text { Focal AT from } \\
\text { the vein of } \\
\text { Marshall. - Focal } \\
\text { AT from the } \\
\text { anterior LA wall. } \\
\text { - Prophylactic } \\
\text { posterior LA } \\
\text { box. }\end{array}$ \\
\hline
\end{tabular}

$\mathrm{ASL}=$ anteroseptal line (line between mitral annulus and right superior pulmonary vein); AT = atrial 
tachycardia; AVNRT = atrioventricular nodal reentrant tachycardia; CTI = cavotricuspid isthmus; IVC = inferior vena cava; LA = left atrium; LIPV = left inferior pulmonary vein; LSPV = left superior pulmonary vein; MAL = modified anterior line (line between mitral annulus and left superior pulmonary vein); PVI = pulmonary vein isolation; RIPV = right inferior pulmonary vein; RSPV = right superior pulmonary vein; $\mathrm{STD}=$ spatiotemporal dispersion; $\mathrm{SVC}=$ superior vena cava.

* Sites with spatiotemporal dispersion plus non-continuous fractionation were only mapped if no rotors were present or if rotor ablation was ineffective.

+ Spontaneous conversion from AF to stable AT occurred after rotor mapping in the left atrium was completed (no rotors were found).

Table 3. Clinical and procedural variables of patients with and without recurrences of atrial arrhythmias.

\begin{tabular}{lll}
\hline & Patients without recurrences $(\mathrm{n}=10)$ & Patients with recurrences $(\mathrm{n}=8)$ \\
\hline Age (years) & $71.1 \pm 11.2$ & $73.2 \pm 5.3$ \\
Females $\%)$ & $4(40 \%)$ & $5(63 \%)$ \\
Left ventricular ejection fraction $(\%)$ & $56[42-60]$ & $60[55-66]$ \\
Indexed left atrial volume $\left(\mathrm{ml} / \mathrm{m}^{2}\right)$ & $33.6 \pm 10.6$ & $40.2 \pm 13.0$ \\
Significant structural cardiopathy & $5(50 \%)$ & $4(50 \%)$ \\
Previous atrial fibrillation & $6(60 \%)$ & $5(63 \%)$ \\
Prior ablation procedures & $9(90 \%)$ & $2(25 \%)$ \\
Prior cardiac surgery & $2(20 \%)$ & $2(25 \%)$ \\
Procedural time (min) & $260 \pm 66$ & $267 \pm 72$ \\
Presence of rotors & $7(70 \%)$ & $6(75 \%)$ \\
Use of contact force-sensing ablation catheters & $3(30 \%)$ & $3(37 \%)$ \\
Pulmonary vein isolation $*$ & $7(70 \%)$ & $4(50 \%)$ \\
Cavotricuspid isthmus ablation * & $8(80 \%)$ & $7(88 \%)$ \\
\hline
\end{tabular}

Data are shown as mean $\pm \mathrm{SD}$, median [interquartile range] or number (percentage), when appropriate. No statistical comparisons between patients with or without recurrences were made because of the limited sample size.

* Performed during the index or previous procedures. 